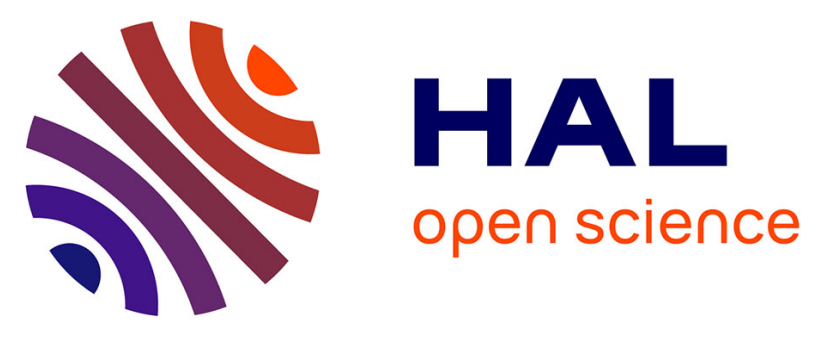

\title{
Impact of anion vacancies on the local and electronic structures of iron-based oxyfluoride electrodes
}

\author{
Mario Burbano, Mathieu Duttine, Benjamin J. Morgan, Olaf Borkiewicz, \\ Karena W. Chapman, Alain Wattiaux, Alain Demourgues, Henri Groult, \\ Mathieu Salanne, Damien Dambournet
}

\section{To cite this version:}

Mario Burbano, Mathieu Duttine, Benjamin J. Morgan, Olaf Borkiewicz, Karena W. Chapman, et al.. Impact of anion vacancies on the local and electronic structures of iron-based oxyfluoride electrodes. Journal of Physical Chemistry Letters, 2018, 10 (1), pp.107-112. 10.1021/acs.jpclett.8b03503 . hal02007633

\section{HAL Id: hal-02007633 \\ https://hal.science/hal-02007633}

Submitted on 12 Jul 2019

HAL is a multi-disciplinary open access archive for the deposit and dissemination of scientific research documents, whether they are published or not. The documents may come from teaching and research institutions in France or abroad, or from public or private research centers.
L'archive ouverte pluridisciplinaire $\mathbf{H A L}$, est destinée au dépôt et à la diffusion de documents scientifiques de niveau recherche, publiés ou non, émanant des établissements d'enseignement et de recherche français ou étrangers, des laboratoires publics ou privés. 


\section{Impact of Anion Vacancies on the Local and}

\section{Electronic Structures of Iron-based Oxyfluoride}

\section{Electrodes}

Mario Burbano, ${ }^{1,6}$ Mathieu Duttine, ${ }^{2}$ Benjamin J Morgan, ${ }^{3,4}$ Olaf J Borkiewicz, ${ }^{5}$ Karena W Chapman, ${ }^{5}$ Alain Wattiaux, ${ }^{2}$ Alain Demourgues, ${ }^{2}$ Henri Groult, ${ }^{1,6}$ Mathieu Salanne, ${ }^{1,6}$ Damien Dambournet. ${ }^{1,6, *}$

${ }^{1}$ Sorbonne Université, CNRS, Physico-chimie des électrolytes et nano-systèmes interfaciaux, PHENIX, F-75005 Paris, France

${ }^{2}$ CNRS, Univ Bordeaux, ICMCB, UPR 9048, F-33600 Pessac, France.

${ }^{3}$ Department of Chemistry, University of Bath, Claverton Down, BA2 7AY, United Kingdom.

4 The Faraday Institution, Quad One, Harwell Science and Innovation Campus, Didcot, United Kingdom.

${ }^{5}$ X-ray Science Division, Advanced Photon Source, Argonne National Laboratory, Argonne, Illinois, USA.

${ }^{6}$ Réseau sur le Stockage Electrochimique de l'Energie (RS2E), FR CNRS 3459, 80039 Amiens Cedex, France. 


\section{AUTHOR INFORMATION}

\section{Corresponding Author}

* damien.dambournet@sorbonne-universite.fr

ABSTRACT. The properties of crystalline solids can be significantly modified by deliberately introducing point defects. Understanding these effects, however, requires understanding the

changes in geometry and electronic structure of the host material. Here we report the effect of forming anion vacancies, via dehydroxylation, in a hexagonal-tungsten-bronze-structured iron oxyfluoride, which has potential use as a lithium-ion battery cathode. Our combined pairdistribution function and density-functional-theory analysis indicates that oxygen vacancy formation is accompanied by a spontaneous rearrangement of fluorine anions and vacancies, producing dual pyramidal $\left(\mathrm{FeF}_{4}\right)-\mathrm{O}-\left(\mathrm{FeF}_{4}\right)$ structural units containing five-fold-coordinated Fe atoms. The addition of lattice oxygen introduces new electronic states above the top of the valence band, with a corresponding reduction in the optical band gap from $4.05 \mathrm{eV}$ to $2.05 \mathrm{eV}$. This band gap reduction relative to the $\mathrm{FeF}_{3}$ parent material is correlated with a significant improvement in lithium insertion capability relative to defect-free compound.

\section{TOC GRAPHICS}




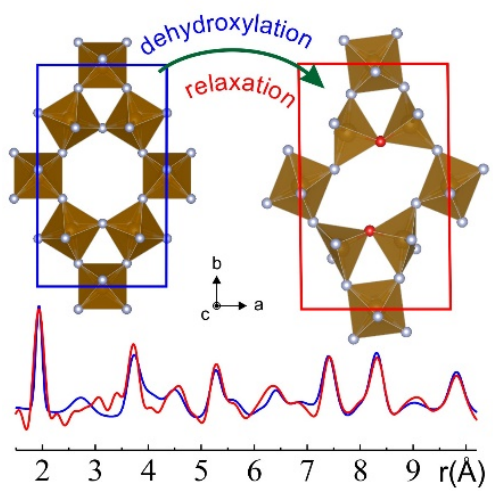

KEYWORDS. Defects, pair distribution function, density functional theory, band gap engineering.

The search for high capacity electrodes for rechargeable lithium-ion batteries has led to many materials being proposed as potential candidates. Iron fluorides contain earth-abundant iron as their redox-active species, and have a high theoretical capacity (237 $\mathrm{mA} \mathrm{h} \mathrm{g}^{-1}$ for $1 \mathrm{e}$ ) and a high voltage vs. $\mathrm{Li}^{+} / \mathrm{Li}$ of $3.0 \mathrm{~V}-3.3 \mathrm{~V} .{ }^{1}$ Metal fluorides, however, are electronic insulators characterized by large bandgaps ( $>3 \mathrm{eV}$ ), which limits their electrochemical properties due to poor electronic conductivities. To overcome this limitation, several approaches have been proposed, including: (i) the synthesis of nanocomposites containing carbon; ${ }^{2}$ (ii) the preparation of oxyfluorinated compounds with reduced band gaps, which can produce complex electrochemical behaviour; ${ }^{3,4,5}$ (iii) the stabilization of open-frameworks such as the hexagonal-tungsten-bronze ${ }^{6}$ (HTB) and pyrochlore ${ }^{7}$ type structures, that can be functionalized with single wall nanotubes (SWNTs) $^{8}$; (iv) surface engineering to protect the electrode materials ${ }^{9}$; and (v) the introduction of anionic vacancies ${ }^{10}$ in an oxyfluoride HTB-type structure, which can be denoted $\mathrm{FeF}_{3-x} \mathrm{O}_{x / 2} \square_{x / 2}$, with $\square$ referring to anionic vacancies. 
One proven strategy for improving the electrochemical performance of electrode materials is to deliberately introduce defects, such as vacancies. ${ }^{10-13}$ At present, a general understanding of this effect is absent. Building such an understanding requires a detailed characterization of the relevant defects, to allow the coupled changes in stoichiometry, crystal geometry, and electronic structure to be resolved. We have previously reported the stabilization of anionic vacancies in an iron oxyfluoride compound $\mathrm{FeF}_{3-x} \mathrm{O}_{x / 2} \square_{x / 2}$, studied using x-ray diffraction analysis and Mössbauer spectroscopy. ${ }^{10}$ We previously reported that the substitution of fluoride by oxide anions is accompanied by the formation of anionic vacancies, producing undercoordinated iron atoms. The effect of fluorine substitution by oxygen and accompanying anion vacancy formation on the local structure has yet to be fully assessed. Here, we describe a combined experimental and computational study, performed to resolve the changes in crystal geometry and electronic structure induced by concomitant oxygen substitution and anion vacancy formation.

The vacancy-containing iron oxyfluoride compound $\mathrm{FeF}_{3-x} \mathrm{O}_{x / 2} \square_{x / 2}$ was prepared by a two-step thermal decomposition process of $\mathrm{FeF}_{3} .3 \mathrm{H}_{2} \mathrm{O}$ : a compound that can be produced from spent liquor from stainless steel production. ${ }^{14}$ Using a self-generated atmosphere, $\mathrm{FeF}_{3} .3 \mathrm{H}_{2} \mathrm{O}$ was decomposed into a HTB-structured hydroxyfluoride compound $\mathrm{FeF}_{3-x}(\mathrm{OH})_{x} \cdot n \mathrm{H}_{2} \mathrm{O}(n \leq 0.33)$, denoted $\mathrm{FeF}_{3}$ ${ }_{x}(\mathrm{OH})_{x}$ hereafter. ${ }^{15}$ This sample was heat treated at $250{ }^{\circ} \mathrm{C}$ for $12 \mathrm{~h}$, and $350{ }^{\circ} \mathrm{C}$ for $1 \mathrm{~h}$ to form $\mathrm{FeF}_{3-x} \mathrm{O}_{x / 2} \square_{x / 2}$ with $\mathrm{x} \sim 0.4$. X-ray diffraction confirmed the phase purity of the vacancy-containing HTB structure (Figure S1). The presence of anionic vacancies was ascertained by ${ }^{57} \mathrm{Fe}$ Mössbauer spectroscopy through the characteristic signature of five-fold coordinated iron (Figure S2).${ }^{10}$ In agreement with our previous studies, ${ }^{10,16}$ the implementation of anionic vacancies led to a significant improvement of the electrochemical properties as compare to the defect-free compound $\mathrm{FeF}_{3-x}(\mathrm{OH})_{x}$. Using a similar electrode processing, we showed that $\mathrm{FeF}_{3-x}(\mathrm{OH})_{x}$ could only 
reversibly inserted $0.05 \mathrm{Li}^{+}$per Fe while introducing vacancies improved the reversibility up to $0.6 \mathrm{Li}^{+}$per Fe (Figure S3).

The thermal decomposition of the precursor $\mathrm{FeF}_{3} .3 \mathrm{H}_{2} \mathrm{O}$ is associated with a distinctive color change, from the light green color of $\mathrm{FeF}_{3} .3 \mathrm{H}_{2} \mathrm{O}$ to a brownish hue for $\mathrm{FeF}_{3-\mathrm{x}} \mathrm{O}_{x / 2} \square_{x / 2}$. To track the evolution of the optical band-gap, we collected diffuse reflectance UV-visible spectrophotometry data, which were translated into Kubelka-Munk ${ }^{17}$ absorption spectra. The resulting data for $\mathrm{FeF}_{3 .} 3 \mathrm{H}_{2} \mathrm{O}, \mathrm{FeF}_{3-x}(\mathrm{OH})_{x}$ and $\mathrm{FeF}_{3-x} \mathrm{O}_{x / 2} \square_{x / 2}$ are shown in Figure 1. On decomposition, the adsorption edge is slightly red-shifted from $\mathrm{FeF}_{3} .3 \mathrm{H}_{2} \mathrm{O}\left(E_{\text {gap }}=4.05 \mathrm{eV}\right)$ to $\mathrm{FeF}_{3-x}(\mathrm{OH})_{x} \cdot n \mathrm{H}_{2} \mathrm{O}\left(E_{\text {gap }}\right.$ $=3.75 \mathrm{eV}$ ). These band-gap energies indicate an electronic insulator behavior, which suggests that substituting F with $\mathrm{OH}$ does not significantly alter the electronic properties of this material. ${ }^{18}$ After a second thermal treatment to form anionic vacancies, however, the absorption band is more strongly read-shifted, giving an optical band-gap energy for $\mathrm{FeF}_{3-x} \mathrm{O}_{x / 2} \square_{x / 2}$ of $E_{\text {gap }} \approx 2.05 \mathrm{eV}$. This large band-gap reduction means this anion-vacant material may be considered a semiconductor, rather than an insulator. This distinction is usually associated with an increase in electronic conductivity, because of the relative ease with which charge carriers can now be thermally excited across the fundamental band gap.

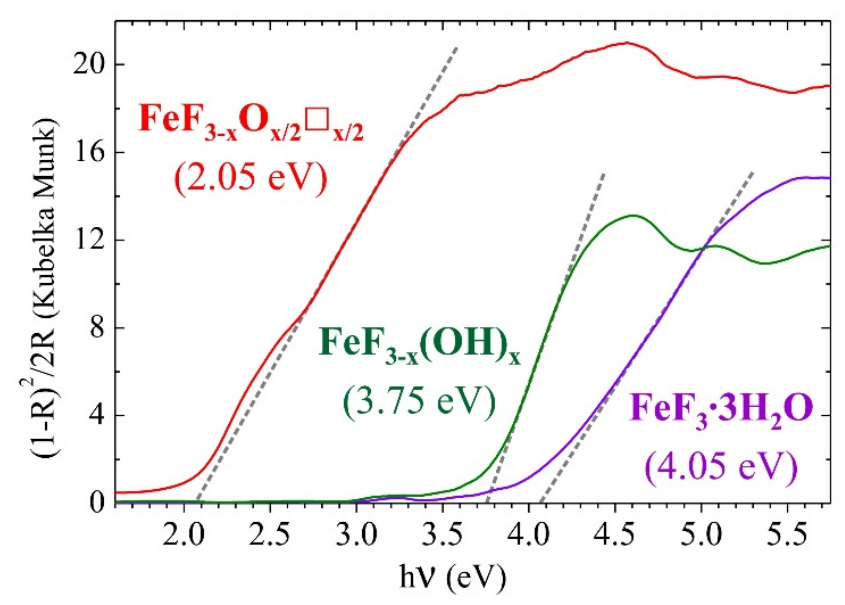


Figure 1. Kubelka-Munk absorption spectra of $\mathrm{FeF}_{3} .3 \mathrm{H}_{2} \mathrm{O}, \mathrm{HTB}_{-}-\mathrm{FeF}_{3-x}(\mathrm{OH})_{x}$ and $\mathrm{HTB}-\mathrm{FeF}_{3-}$ ${ }_{x} \mathrm{O}_{x / 2} \square_{x / 2}$.

The atomic structure of $\mathrm{FeF}_{3-\mathrm{x}} \mathrm{O}_{\mathrm{x} / 2} \square_{\mathrm{x} / 2}$ was probed by the pair distribution function (PDF) method obtained by Fourier transformation of the total scattering data. ${ }^{19}$ PDF describes structural features across different scales, giving information about local-, intermediate- and long-range order. ${ }^{20}$ We refined the structure of $\mathrm{FeF}_{3-\mathrm{x}} \mathrm{O}_{\mathrm{x} / 2} \square_{\mathrm{x} / 2}$ using the following procedure: (1) the structural model was refined against the PDF data with the exclusion of the short-range order, i.e., in the $7 \AA-50 \AA$ range. In this region, the HTB-type structure (space group: $\mathrm{Cmcm})^{21}$ provides an excellent fit to the data, with a reliability factor $R_{\mathrm{w}}=18.4 \%$ (Figure 2a). (2) Including the local structure, i.e., the $1 \AA-7 \AA$ range, increased the reliability factor to $R_{w}=44.5 \%$ (Figure $2 \mathbf{b}$ ). While the ideal $\mathrm{FeF}_{3}$ structure provides a good description of the average structure at intermediateto-long range scales, over shorter distances the local structure shows significant deviations (cf. the difference curve, Figure 2b), which we attribute to local structural distortions due to anionic vacancies.

To more clearly visualize the local structure in $\mathrm{FeF}_{3-\mathrm{x}} \mathrm{O}_{\mathrm{x} / 2} \square_{\mathrm{x} / 2}$, differential PDF (d-PDF) was obtained by subtracting re-scaled PDFs of $\mathrm{FeF}_{3-x}(\mathrm{OH})_{x}$ and $\mathrm{FeF}_{3-\mathrm{x}} \mathrm{O}_{\mathrm{x} / 2} \square_{\mathrm{x} / 2}$ (Figure 2c). The d-PDF allows identification of specific interatomic-distances that appear with the introduction of anionic vacancies at $1.83 \AA-2.04 \AA$, $3.08 \AA$, $3.40 \AA$ and $6.23 \AA$. The structural distortion introduced by forming anion vacancies therefore extends beyond the first coordination sphere of iron, which suggests the emergence of new structural motifs. 

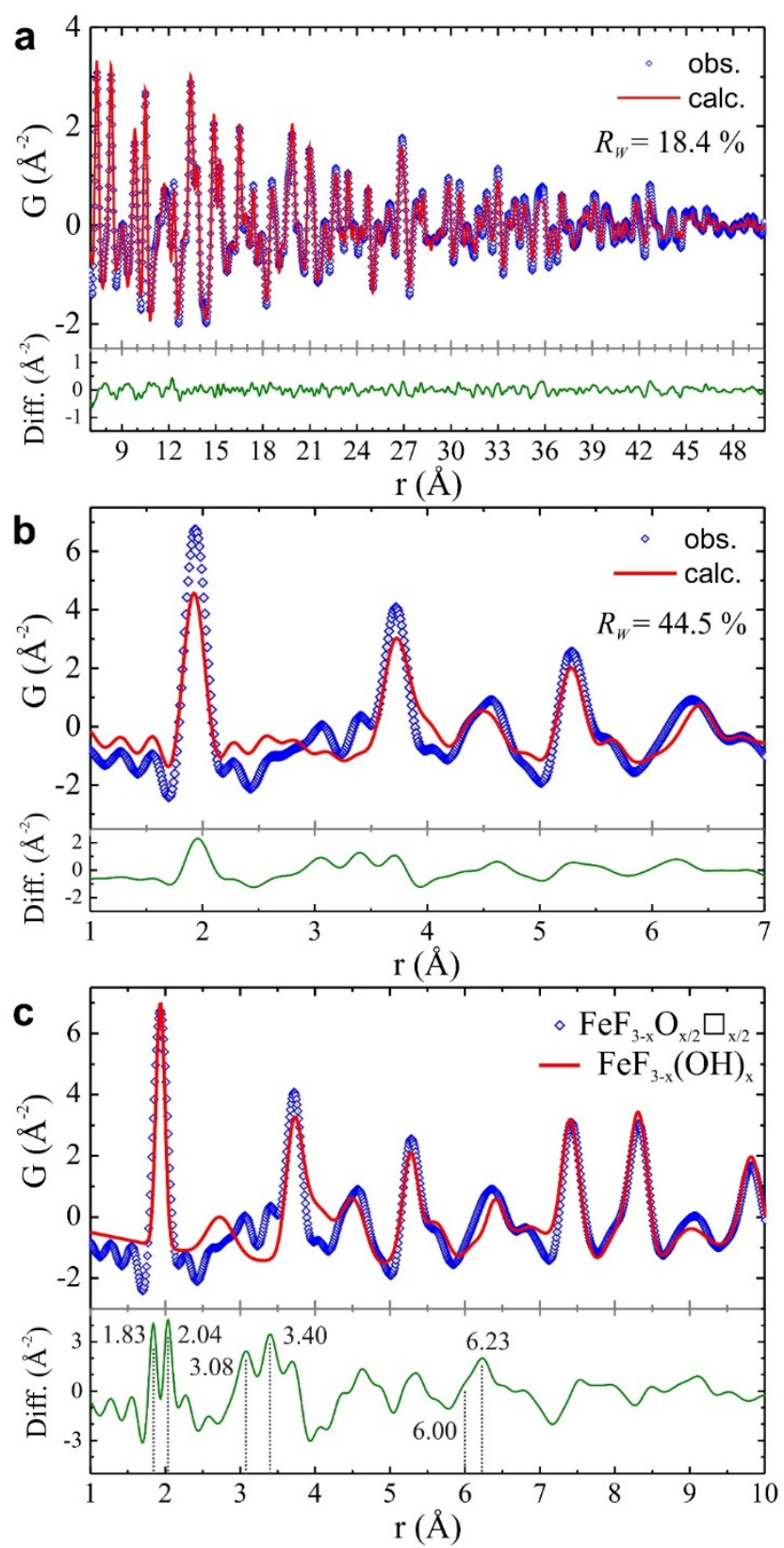

Figure 2. PDF refinement of $\mathrm{FeF}_{3-\mathrm{x}} \mathrm{O}_{\mathrm{x} / 2} \square_{\mathrm{x} / 2}$ using the HTB-type structure. a. Intermediate-long range region (7 $\AA-50 \AA$ ). b. Short range region ( $1 \AA$-7 $\AA$ ). c. Re-scaled PDFs of FeF 3 -x $(\mathrm{OH})_{\mathrm{x}}$ and $\mathrm{FeF}_{3-\mathrm{x}} \mathrm{O}_{\mathrm{x} / 2} \square_{\mathrm{x} / 2}$ and the corresponding differential PDF (d-PDF).

To better understand the structural changes that accompany dehydroxylation, we performed a series of density functional theory (DFT) calculations, modelling stoichiometric $\mathrm{FeF}_{3}\left(\mathrm{Fe}_{12} \mathrm{~F}_{36}\right)$, 
hydroxylated $\mathrm{FeF}_{3}\left(\mathrm{Fe}_{12} \mathrm{~F}_{36-x}(\mathrm{OH})_{x}\right)$, and dehydroxylated $\mathrm{FeF}_{3}\left(\mathrm{Fe}_{12} \mathrm{~F}_{36-x} \mathrm{O}_{x-y} \square_{y}\right)$. We performed calculations at two defect concentrations: the first considered hydroxylation at two anion sites, followed by dehydroxylation to form a single $\square_{F}+O_{F}$ defect pair; the second considered hydroxylation at four anion sites, followed by dehydroxylation to form two $\square_{\mathrm{F}}+\mathrm{O}_{\mathrm{F}}$ defect pairs. In both cases, geometry optimization of the dehydroxylated model gives a spontaneous reorganization of $\mathrm{F}^{-}$anions, corresponding to $\mathrm{FeF}_{5} \mathrm{O}+\mathrm{FeF}_{5} \rightarrow \mathrm{FeF}_{4} \mathrm{O}+\mathrm{FeF}_{6}$ changes in $\mathrm{Fe}$ coordination environments. Here, we discuss this relaxation in the double vacancy system, while the equivalent details for the single vacancy system are given in the SI. Figure 3 shows the geometries of HTB- $\mathrm{Fe}_{12} \mathrm{~F}_{36}$ and $\mathrm{Fe}_{12} \mathrm{~F}_{32} \mathrm{O}_{2} \square_{2}$. For HTB-Fe ${ }_{12} \mathrm{~F}_{36}$, we show a starting unrelaxed structure (i.e., at a corresponding $\mathrm{Fe}_{12} \mathrm{~F}_{32}(\mathrm{OH})_{4}$ geometry) and the final optimized structure. For $\mathrm{Fe}_{12} \mathrm{~F}_{32} \mathrm{O}_{2} \square_{2}$, we show only the final optimized geometry. Before relaxation, the anion vacancies in $\mathrm{Fe}_{12} \mathrm{~F}_{32} \mathrm{O}_{2} \square_{2}$ are on opposite sides of the hexagonal cavity. These vacancies give pairs of undercoordinated Fe sites with pure F-coordination, $\mathrm{FeF}_{n}(n<6)$, and with mixed F/O-coordination, $\mathrm{FeF}_{m} \mathrm{O}$, separated by the anion vacancies. The under-coordinated $\mathrm{FeF}_{n}(n<6)$ centers have formal oxidation states less than +3 , which are balanced by six-coordinate $\mathrm{FeF}_{5} \mathrm{O}$ centers with formal oxidation states of +3.5 . Geometry optimization involves a structural rearrangement where $\mathrm{F}$ ions leave $\mathrm{FeF}_{5} \mathrm{O}$ units and join previously under-coordinated $\mathrm{FeF}_{n}$ units. This produces a structure where every Fe now has a formal +3 oxidation state, and oxide anions link vertex-sharing pairs of square-pyramidal $\mathrm{FeF}_{4} \mathrm{O}$ units. For the double vacancy system, the formation of defect pairs on opposite sides of the hexagonal cavity is characterized by a specific set of interatomic distances, which closely match those observed in the d-PDF (Table 1), allowing all distances to be assigned. 


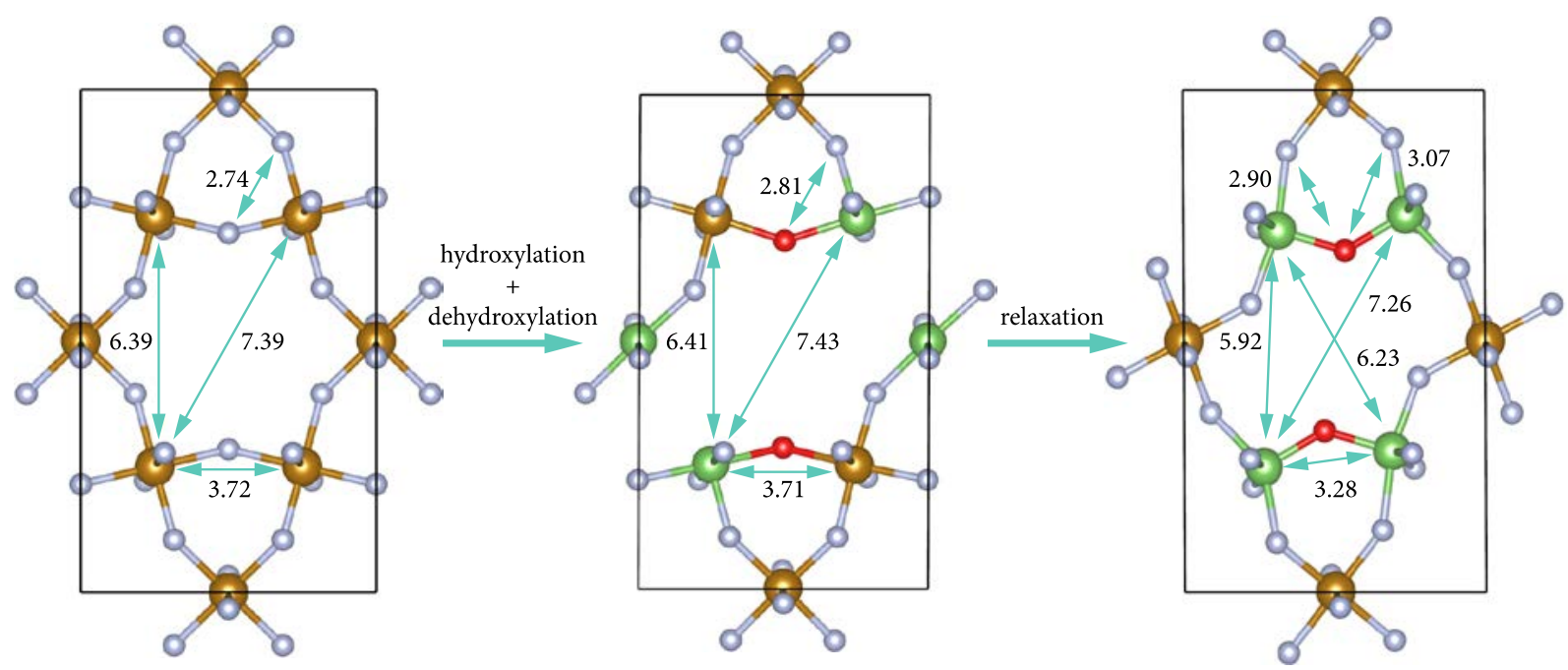

Figure 3. Left panel: optimized structure of the $\mathrm{Fe}_{12} \mathrm{~F}_{36}$ cell. Middle to right panels: evolution of the structure of the $\mathrm{Fe}_{12} \mathrm{~F}_{32} \mathrm{O}_{2} \square_{2}$ cell before and after relaxation. Views are along the $c$-axis. Distances are given in Angstroms. The structure files used to generate this plot are available under CC-BY-4.0 licence as part of ref. 22.

Table 1. Interatomic distances obtained from the differential PDF (d-PDF), DFT calculations (double vacancy model) and corresponding assignments.

\begin{tabular}{|l|l|l|}
\hline d-PDF $(\AA)$ & DFT $(\AA)$ & Assignments \\
\hline 1.83 & 1.79 & Fe-O \\
2.04 & 1.97 & Fe-F \\
3.08 & 3.07 & O-F \\
3.40 & 3.28 & Fe-Fe \\
6.23 & 6.23 & Fe-Fe \\
\hline
\end{tabular}

The assignment of d-PDF distances to pairs of bipyramidal $\mathrm{FeF}_{4} \square-\mathrm{O}-\mathrm{FeF}_{4} \square$ units indicates a degree of defect clustering. The x-ray diffraction data, however, appear to not show any superstructure peaks, which suggests that this clustering does not lead to long-ranged ordering of anion vacancies. 
The angular-momentum-projected densities of state (pDOS) from our DFT calculations provide information about how defects change the electronic structure of $\mathrm{HTB}^{-F e F}$ (Figure 4). In stoichiometric $\mathrm{HTB}_{-} \mathrm{FeF}_{3}$ (top panel) the valence band is dominated by the $\mathrm{F} 2 \mathrm{p}$ states and the conduction band is dominated by Fe 3d states. Hydroxylation (middle panel) introduces new occupied O 2p defect states slightly above the top of the valence band. Dehydroxylation to form anion vacancies (bottom panel) pushes these $\mathrm{O} 2 \mathrm{p}$ states further into the gap. Compared to stoichiometric $\mathrm{HTB}-\mathrm{FeF}_{3}$, these $\mathrm{O} 2 \mathrm{p}$ states reduce the energy gap between highest-occupied and lowest-unoccupied states. The relaxed dehydroxylated structure contains both six-coordinate FeF6 and five-coordinate $\mathrm{FeF}_{4} \mathrm{O}$ units. By projecting the d-state orbital character of the charge density for these 5-coordinate and 6-coordinate Fe sites (Figure S5), we observe that d-states from the 5coordinate Fe centres mix with the $\mathrm{O} 2 \mathrm{p}$ defect states above the conduction band maximum, and contribute to the effective band-gap reduction.

Calculated absorption spectra for these three systems show a sequential reduction in the onset of optical absorption in moving from $\mathrm{HTB}-\mathrm{FeF}_{3}$ to the hydroxylated system, and then to the dehydroxylated system (Figure 4, bottom). While the reduction in optical band gap predicted by these calculations is not as large as we observe in our experimental absorption spectra (Figure 1), the correct qualitative trend is reproduced, which supports our proposition that this change from insulating to semiconducting behavior is caused by the introduction of lattice oxygen defects. 

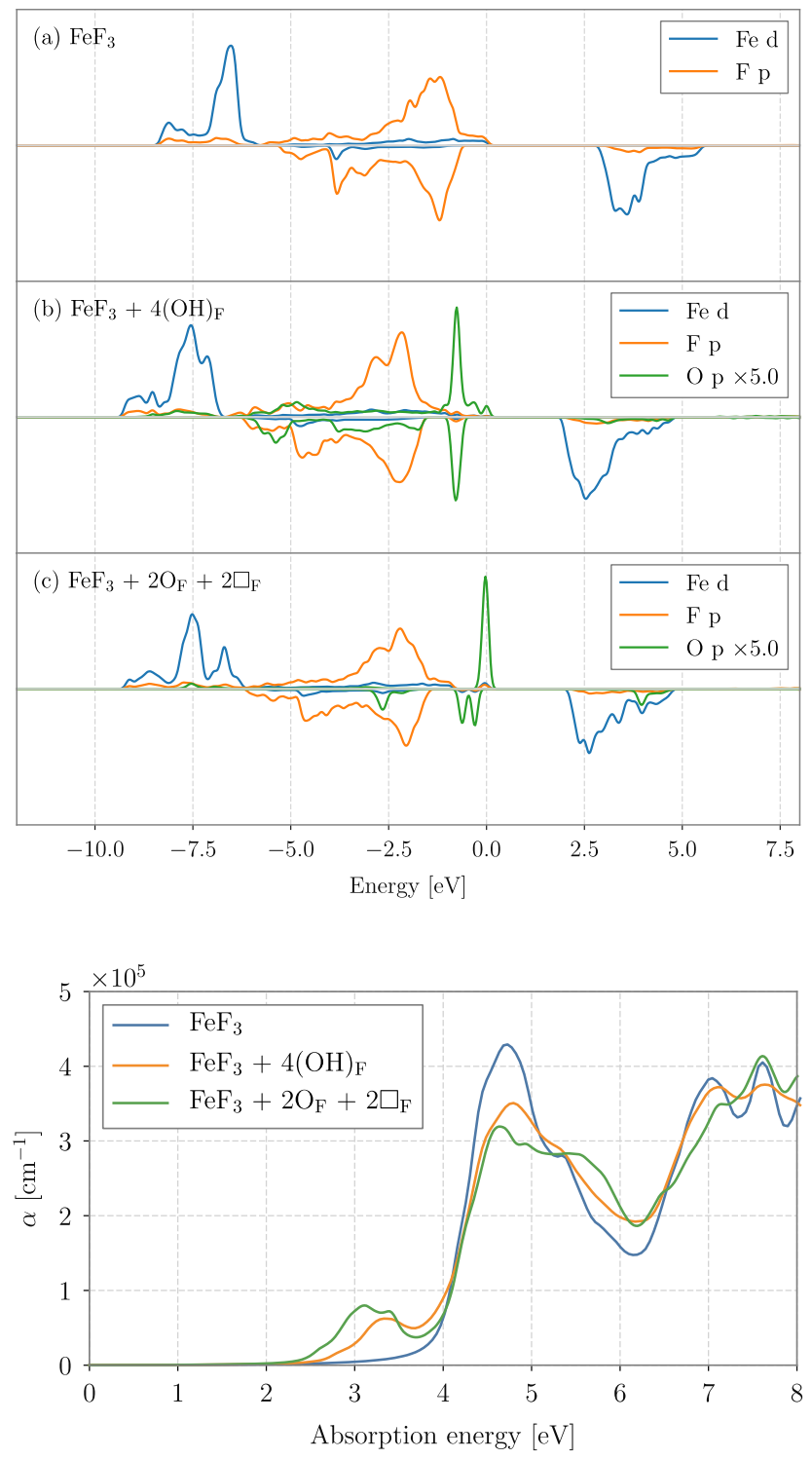

Figure 4. top. PBEsol calculated electronic densities of states (EDOS) for (a) HTB-FeF3, (b)

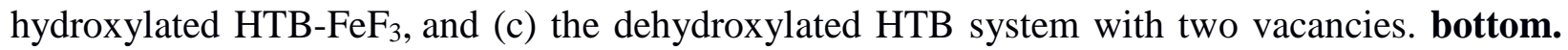
PBEsol calculated absorption coefficients, $\alpha$, for stoichiometric $\mathrm{FeF}_{3}$, hydroxylated $\mathrm{FeF}_{3}+4(\mathrm{OH})_{\mathrm{F}}$, and dehydroxylated $\mathrm{FeF}_{3}+2 \mathrm{O}_{\mathrm{F}}+2 \square_{\mathrm{F}}$. Source: source data, figure files, and plotting scripts are available under the CC-BY-4.0 licence as part of ref. 22. 
To conclude, we investigated the local structural changes induced by the stabilization of anionic vacancies in an iron oxyfluoride electrode material. The combination of the PDF and DFTcalculations used in this study made it possible to gain a clearer understanding of the local structure of anionic vacancies in $\mathrm{HTB}_{-} \mathrm{FeF}_{3}$. The PDF enabled us to visualize the atomic distortion induced by the vacancies. It revealed that the structure locally re-arranges at a scale range of several angstroms. Differential PDFs clearly identified new interatomic-distances that appear after the introduction of anionic vacancies. DFT-calculations were used to model an HTB cell containing two anionic vacancies. After the cell relaxation, the under-coordinated Fe form dimers that induced new structural motifs in the structure with inter-atomic distances that match those observed by PDF, hence validating the proposed model. Moreover, we identified the presence of defect states of $\mathrm{O} 2 \mathrm{p}$ character above the valence band upon hydroxylation of $\mathrm{HTB}-\mathrm{FeF}_{3}$. These states shift further towards the conduction band upon the introduction of vacancies. As a result, vacancies drastically modify the electronic structure moving from electronic insulator to a semiconductor, which is correlated with the observed improvement of the electrochemical properties using this material as an electrode in a lithium-ion cell.

\section{EXPERIMENTAL AND COMPUTATIONAL METHODS}

Synthesis. The precursor $\mathrm{FeF}_{3} \cdot 3 \mathrm{H}_{2} \mathrm{O}$ was synthetized according to the reference ${ }^{15}$. $\mathrm{FeF}_{3-x} \mathrm{O}_{x / 2} \square_{x / 2}$ was prepared by a two-steps thermal decomposition process of $\mathrm{FeF}_{3} .3 \mathrm{H}_{2} \mathrm{O}$. First, $\mathrm{FeF}_{3} .3 \mathrm{H}_{2} \mathrm{O}$ was decomposed at $150{ }^{\circ} \mathrm{C}$ under air for two hours using the self-generated atmosphere method. A subsequent heat treatment was performed at $250{ }^{\circ} \mathrm{C}$ for $12 \mathrm{~h}$ and $350{ }^{\circ} \mathrm{C}$ for one hour to form $\mathrm{FeF}_{3}$ ${ }_{x} \mathrm{O}_{x / 2} \square_{x / 2}$. 
X-ray diffraction (XRD) analysis. Powder XRD patterns were recorded on PANalytical X'Pert (Co-K $\alpha$ or $\mathrm{Cu}-\mathrm{K} \alpha_{1}$ radiations) diffractometers in a Bragg-Brentano geometry $(\theta-2 \theta)$.

Mössbauer spectroscopy. Measurements were performed at room temperature using a constant acceleration Halder type spectrometer with a room temperature ${ }^{57} \mathrm{Co}$ source in transmission geometry. The velocity was calibrated using pure $\alpha$-Fe as the standard material. Mossbauer spectra were reconstructed using the WinNormos ${ }^{\circledR}$ software (Wissenschaftliche Elektronik GmbH).

UV-Visible absorption analysis. Diffuse reflectance spectra $R(\lambda)$ were recorded at room temperature using a Cary 17 spectrophotometer with an integration sphere in the wavelength range of 200-800 nm and a $1 \mathrm{~nm}$ step (bandwidth : $2 \mathrm{~nm}$ ). Halon was used as white reference.

Pair Distribution Function (PDF) analysis. High energy X-ray data were collected at the 11-IDB station at the Advanced Photon Source (Argonne National Laboratory). After corrections (background and Compton scattering), PDFs were extracted from the data using PDFgetX2 sofware. ${ }^{23}$ Refinements of the PDF data were performed using PDFgui. ${ }^{24}$

Electrochemical characterization. Electrochemical reactions with lithium were evaluated using coin cells comprising an iron-based fluoride and metallic lithium as electrodes. The composition of iron-based fluorides Electrodes was $75 \mathrm{wt} \%$ active materials, $15 \mathrm{wt} . \%$ acetylene black as the conductive agent, and $10 \mathrm{wt} . \%$ polyvinylidene difluoride as the binder. The different components were hand milled with NMP solvent prior to deposit on an aluminum foil. The prepared slurry was spread by a Doctor-blade. The area of the electrode was $1.0 \mathrm{~cm}^{2}$ with a typical mass loading around $3 \mathrm{mg}$. The electrolyte consisted of the commercially available LP30 (1.0M LiPF6 dissolved in a mixture of ethylene carbonate and ethyl methyl carbonate (3:7 volume ratio). Cells were cycled between 2 and $4.2 \mathrm{~V}$ at $50 \mathrm{~mA} / \mathrm{g}$ current density.

\section{Computational methods.}


Our density functional theory (DFT) calculations were performed using the code VASP ${ }^{25,26}$ with valence electrons described using a plane-wave basis with a cutoff of $520 \mathrm{eV}$. Interactions between core and valence electrons were described using the projector augmented wave (PAW) approach ${ }^{27}$, with cores of $[\mathrm{Ar}]$ for $\mathrm{Fe},[\mathrm{He}]$ for $\mathrm{O}$, $[\mathrm{He}]$ for $\mathrm{F}$, and $\left[\mathrm{H}^{+}\right]$for $\mathrm{H}$. Calculations used the revised Perdew-Burke-Ernzerhof generalized-gradient approximation PBEsol functional ${ }^{28}$, with a Dudarev $+\mathrm{U}$ correction applied to the Fe d states $(\mathrm{GGA}+U)^{29,30}$, or the hybrid HSE06 functional ${ }^{31}$. For the PBEsol $+U$ calculations, we used a value of $U=5.3 \mathrm{eV}$, taken from the pymatgen MPRelaxSet. ${ }^{32}$ Calculations were performed on $\mathrm{Fe}_{12} \mathrm{Fe}_{36}$ cells, or anion-substituted equivalents. For each stoichometry, we first calculated zero-pressure optimized lattice parameters, by performing a series of constant-volume geometry optimisations and fitting the resulting energyvolume data to the Murnaghan equation of state, before performing a final geometry optimization at these cell parameters. Individual calculations were deemed converged when all atomic forces were smaller than $0.01 \mathrm{eV} \AA^{-1}$. All calculations were spin polarized, and we assumed ferromagnetic configurations. $k$-space sampling used a $4 \times 2 \times 4$ Monkhorst-Pack grid. A data set containing all DFT calculation inputs and outputs is available at the University of Bath Data Archive $^{22}$ published under the CC-BY-4.0 license. This dataset includes scripts used for postprocessing and plotting our DFT data.

\section{ASSOCIATED CONTENT}

Supporting Information. X-ray diffraction and Mössbauer analyses, electrochemical characterizations, and additional DFT-calculations data.

\section{AUTHOR INFORMATION}

The authors declare no competing financial interests. 


\section{NOTES:}

The DFT dataset supporting this study is available from the University of Bath Research Data Archive (ref 22, doi.org/10.15125/BATH-00576), published under the CC-BY-4.0 license. This dataset contains all input files and outputs for the VASP DFT calculations, and Python scripts for collating, processing, and plotting the relevant data used in our analysis.

\section{ACKNOWLEDGMENT}

The work done at the Advanced Photon Source, an Office of Science User Facility operated for the U.S. Department of Energy (DOE) Office of Science by Argonne National Laboratory, was supported by the U.S. DOE under Contract No. DE-AC02-06CH11357. A. D., H. G. and D. D. wish to thank the French fluorine network for continuous support. B. J. M. acknowledges support from the Royal Society (Grant No. UF130329), and the Faraday Institution (faraday.ac.uk; EP/S003053/1, grant number FIRG003). Calculations were performed using the Balena High Performance Computing Service at the University of Bath, and the ARCHER supercomputer, through membership of the UK's HPC Materials Chemistry Consortium, funded by EPSRC grant EP/L000202.

\section{REFERENCES}

(1) Amatucci, G. G.; Pereira, N. Fluoride Based Electrode Materials for Advanced Energy Storage Devices. Journal of Fluorine Chemistry 2007, 128 (4), 243-262.

(2) Badway, F.; Cosandey, F.; Pereira, N.; Amatucci, G. G. Carbon Metal Fluoride Nanocomposites High-Capacity Reversible Metal Fluoride Conversion Materials as Rechargeable Positive Electrodes for Li Batteries. J. Electrochem. Soc. 2003, 150 (10), A1318-A1327.

(3) Pereira, N.; Badway, F.; Wartelsky, M.; Gunn, S.; Amatucci, G. G. Iron Oxyfluorides as High Capacity Cathode Materials for Lithium Batteries. J. Electrochem. Soc. 2009, 156 (6), A407-A416.

(4) Chevrier, V. L.; Hautier, G.; Ong, S. P.; Doe, R. E.; Ceder, G. First-Principles Study of Iron Oxyfluorides and Lithiation of FeOF. Phys. Rev. B 2013, 87 (9), 094118. 
(5) Wiaderek, K. M.; Borkiewicz, O. J.; Castillo-Martínez, E.; Robert, R.; Pereira, N.; Amatucci, G. G.; Grey, C. P.; Chupas, P. J.; Chapman, K. W. Comprehensive Insights into the Structural and Chemical Changes in Mixed-Anion FeOF Electrodes by Using Operando PDF and NMR Spectroscopy. J. Am. Chem. Soc. 2013, 135 (10), 4070-4078.

(6) Li, C.; Gu, L.; Tong, J.; Tsukimoto, S.; Maier, J. A Mesoporous Iron-Based Fluoride Cathode of Tunnel Structure for Rechargeable Lithium Batteries. Adv. Funct. Mater. 2011, 21 (8), 1391-1397.

(7) Li, C.; Yin, C.; Gu, L.; Dinnebier, R. E.; Mu, X.; van Aken, P. A.; Maier, J. An FeF3·0.5H2O Polytype: A Microporous Framework Compound with Intersecting Tunnels for Li and Na Batteries. J. Am. Chem. Soc. 2013, 135 (31), 11425-11428.

(8) Li, C.; Gu, L.; Tong, J.; Maier, J. Carbon Nanotube Wiring of Electrodes for High-Rate Lithium Batteries Using an Imidazolium-Based Ionic Liquid Precursor as Dispersant and Binder: A Case Study on Iron Fluoride Nanoparticles. ACS Nano 2011, 5 (4), 2930-2938.

(9) Zhao, E.; Borodin, O.; Gao, X.; Lei, D.; Xiao, Y.; Ren, X.; Fu, W.; Magasinski, A.; Turcheniuk, K.; Yushin, G. Lithium-Iron (III) Fluoride Battery with Double Surface Protection. Advanced Energy Materials 2018, 8 (26), 1800721.

(10) Duttine, M.; Dambournet, D.; Penin, N.; Carlier, D.; Bourgeois, L.; Wattiaux, A.; Chapman, K. W.; Chupas, P. J.; Groult, H.; Durand, E.; et al. Tailoring the Composition of a Mixed Anion Iron-Based Fluoride Compound: Evidence for Anionic Vacancy and Electrochemical Performance in Lithium Cells. Chemistry of Materials 2014, 26 (14), 4190-4199.

(11) Hahn, B. P.; Long, J. W.; Rolison, D. R. Something from Nothing: Enhancing Electrochemical Charge Storage with Cation Vacancies. Accounts of Chemical Research 2013, 46 (5), 1181-1191.

(12) Li, W.; Corradini, D.; Body, M.; Legein, C.; Salanne, M.; Ma, J.; Chapman, K. W.; Chupas, P. J.; Rollet, A.-L.; Julien, C.; et al. High Substitution Rate in $\mathrm{TiO}_{2}$ Anatase Nanoparticles with Cationic Vacancies for Fast Lithium Storage. Chemistry of Materials 2015, 27 (14), 5014-5019.

(13) Gao, P.; Metz, P.; Hey, T.; Gong, Y.; Liu, D.; Edwards, D. D.; Howe, J. Y.; Huang, R.; Misture, S. T. The Critical Role of Point Defects in Improving the Specific Capacitance of $\delta$-MnO2 Nanosheets. Nature Communications 2017, 8, 14559.

(14) Forsberg, K. M.; Rasmuson, Å. C. Recycling of Waste Pickle Acid by Precipitation of Metal Fluoride Hydrates. Minerals Engineering 2007, 20 (9), 950-955.

(15) Burbano, M.; Duttine, M.; Borkiewicz, O.; Wattiaux, A.; Demourgues, A.; Salanne, M.; Groult, H.; Dambournet, D. Anionic Ordering and Thermal Properties of FeF3·3H2O. Inorg. Chem. 2015, 54 (19), 9619-9625.

(16) Dambournet, D.; Chapman, K. W.; Duttine, M.; Borkiewicz, O.; Chupas, P. J.; Groult, H. Lithium Insertion Mechanism in Iron-Based Oxyfluorides with Anionic Vacancies Probed by PDF Analysis. ChemistryOpen 2015, 4 (4), 443-447.

(17) VON KUBELKA, P. Ein Beitrag Zur Optik Der Farbanstriche. Zeitschrift fur technische Physik 1931, 593-601.

(18) Yang, Z.; Zhang, Z.; Yuan, Y.; Huang, Y.; Wang, X.; Chen, X.; Wei, S. A First-Principle Study of the Effect of $\mathrm{OH}-$ Doping on the Elastic Constants and Electronic Structure of HTB-FeF3. RSC Adv. 2016, 6 (79), 75766-75776.

(19) Keen, D. A. A Comparison of Various Commonly Used Correlation Functions for Describing Total Scattering. J Appl Cryst, J Appl Crystallogr 2001, 34 (2), 172-177. 
(20) Billinge, S. J. L.; Kanatzidis, M. G. Beyond Crystallography: The Study of Disorder, Nanocrystallinity and Crystallographically Challenged Materials with Pair Distribution Functions. Chem. Commun. 2004, No. 7, 749-760.

(21) Leblanc, M.; Ferey, G.; Chevallier, P.; Calage, Y.; De Pape, R. Hexagonal Tungsten Bronze-Type FeIII Fluoride: (H2O)0.33FeF3; Crystal Structure, Magnetic Properties, Dehydration to a New Form of Iron Trifluoride. Journal of Solid State Chemistry 1983, 47 (1), 53-58.

(22) Morgan, B., 2018. DFT dataset: Impact of Anionic Vacancies on the Local and Electronic Structures of Iron-based Oxyfluoride Electrodes. University of Bath Research Data Archive. https://doi.org/10.15125/BATH-00576.

(23) Qiu, X.; Thompson, J. W.; Billinge, S. J. L. PDFgetX2: A GUI-Driven Program to Obtain the Pair Distribution Function from X-Ray Powder Diffraction Data. J. Appl. Cryst. 2004, 37 (4), 678-678.

(24) Farrow, C. L.; Juhas, P.; Liu, J. W.; Bryndin, D.; Božin, E. S.; Bloch, J.; Proffen, T.; Billinge, S. J. L. PDFfit2 and PDFgui: Computer Programs for Studying Nanostructure in Crystals. J. Phys.: Condens. Matter 2007, 19 (33), 335219.

(25) Kresse, G.; Hafner, J. Ab Initio. Phys. Rev. B 1994, 49 (20), 14251-14269.

(26) Kresse, G.; Furthmüller, J. Efficient Iterative Schemes for Ab Initio Total-Energy Calculations Using a Plane-Wave Basis Set. Phys. Rev. B 1996, 54 (16), 11169-11186.

(27) Perdew, J. P.; Burke, K.; Ernzerhof, M. Generalized Gradient Approximation Made Simple. Phys. Rev. Lett. 1996, 77 (18), 3865-3868.

(28) Perdew, J. P.; Ruzsinszky, A.; Csonka, G. I.; Vydrov, O. A.; Scuseria, G. E.; Constantin, L. A.; Zhou, X.; Burke, K. Restoring the Density-Gradient Expansion for Exchange in Solids and Surfaces. Phys. Rev. Lett. 2008, 100 (13), 136406.

(29) Dudarev, S. L.; Liechtenstein, A. I.; Castell, M. R.; Briggs, G. A. D.; Sutton, A. P. Surface States on $\mathrm{NiO}$ (100) and the Origin of the Contrast Reversal in Atomically Resolved Scanning Tunneling Microscope Images. Phys. Rev. B 1997, 56 (8), 4900-4908.

(30) Dudarev, S. L.; Botton, G. A.; Savrasov, S. Y.; Humphreys, C. J.; Sutton, A. P. ElectronEnergy-Loss Spectra and the Structural Stability of Nickel Oxide: An LSDA+U Study. Phys. Rev. B 1998, 57 (3), 1505-1509.

(31) Krukau, A. V.; Vydrov, O. A.; Izmaylov, A. F.; Scuseria, G. E. Influence of the Exchange Screening Parameter on the Performance of Screened Hybrid Functionals. The Journal of Chemical Physics 2006, 125 (22), 224106.

(32) Ong, S. P.; Richards, W. D.; Jain, A.; Hautier, G.; Kocher, M.; Cholia, S.; Gunter, D.; Chevrier, V. L.; Persson, K. A.; Ceder, G. Python Materials Genomics (Pymatgen): A Robust, Open-Source Python Library for Materials Analysis. Computational Materials Science 2013, 68, 314-319. 


\section{Supplementary Information}

\section{Impact of Anionic Vacancies on the Local and Electronic Structures of Iron-based Oxyfluoride Electrodes}

Mario Burbano, ${ }^{1,6}$ Mathieu Duttine, ${ }^{2}$ Benjamin J Morgan, ${ }^{3,4}$ Olaf J Borkiewicz, ${ }^{5}$ Karena W Chapman, ${ }^{5}$ Alain Wattiaux, ${ }^{2}$ Alain Demourgues, ${ }^{2}$ Henri Groult, ${ }^{1,6}$ Mathieu Salanne, ${ }^{1,6}$ Damien Dambournet. ${ }^{1,6^{*}}$

\section{$\underline{\text { X-ray diffraction analysis }}$}

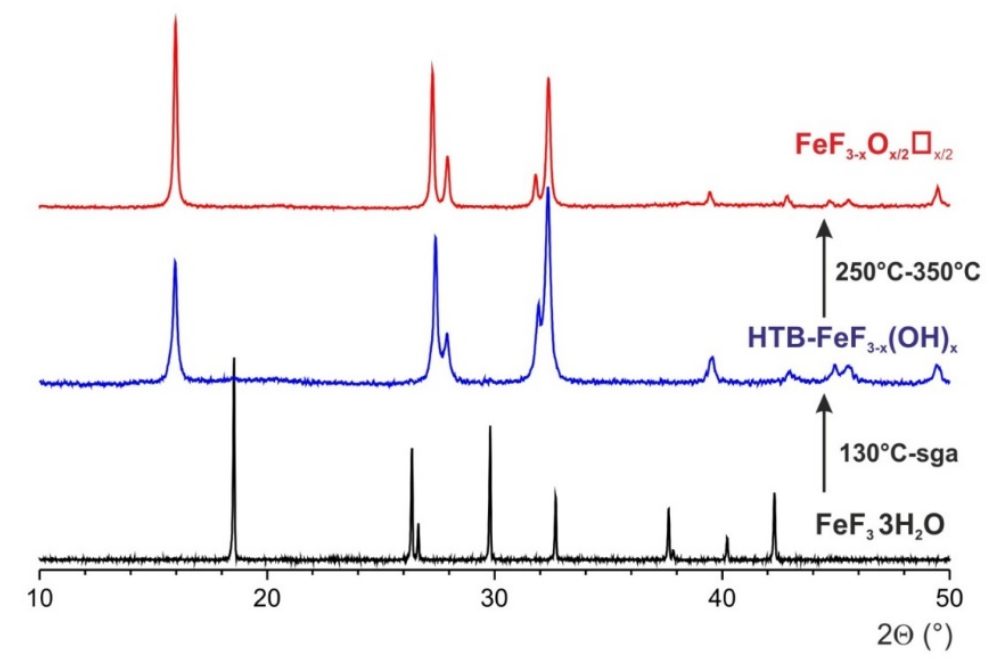

Figure S1. Powder x-ray diffraction patterns of $\beta-\mathrm{FeF}_{3} .3 \mathrm{H}_{2} \mathrm{O}$, the hydroxyfluoride phase obtained by thermal decomposition of the tri-hydrate precursor at $130^{\circ} \mathrm{C}$ under self-generated atmosphere (sga) and $\mathrm{FeF}_{3-\mathrm{x}} \mathrm{O}_{\mathrm{x} / 2} \square_{\mathrm{x} / 2}$ obtained by thermal treatment of $\mathrm{FeF}_{3-\mathrm{x}} \mathrm{OH}_{\mathrm{x}}$ at $250^{\circ} \mathrm{C}$ overnight and $350^{\circ} \mathrm{C}$ for 1 hour under vacuum.

\section{Mössbauer spectroscopy}

Figure S2 shows the ${ }^{57} \mathrm{Fe}$ Mössbauer spectra of $\mathrm{FeF}_{3-x} \mathrm{O}_{x / 2} \square_{x / 2}$ which was reconstructed using three contributions: $\mathrm{Fe}(a)$, accounting for 34\% in relative intensity, which is characterized by an isomer shift of $0.46 \mathrm{~mm} / \mathrm{s}$ and a low quadrupolar spitting value of $0.15 \mathrm{~mm} / \mathrm{s}$, which was ascribed to $\mathrm{Fe}^{3+}$ ions in regular $\mathrm{FeF}_{6}$ octahedra, $\mathrm{Fe}(\mathrm{b})$ which is described by an isomer shift of $0.38 \mathrm{~mm} / \mathrm{s}$ and a quadrupole splitting distribution that is associated to $\mathrm{Fe}^{3+}$ ions located in distorted $\mathrm{FeF}_{6-\mathrm{x}}(\mathrm{OH})_{\mathrm{x}}$ octahedra, finally $\mathrm{Fe}(\mathrm{c})$, accounting for $28 \%$, with an isomer shift at $0.34 \mathrm{~mm} / \mathrm{s}$ and a large quadrupolar splitting distribution with an average value of $1.11 \mathrm{~mm} / \mathrm{s}$ (Table S1). This last signal is due to five-fold coordinated $\mathrm{Fe}^{3+}$ ions and thus attests to the presence of anionic vacancies. Note that the observed differences in isomer shift values of $\mathrm{Fe}(\mathrm{a})$ and $\mathrm{Fe}(\mathrm{b})$ clearly evidenced a drastic change of the ionic character of the metal-ligand bonds through the fluorine substitution by $\mathrm{OH}^{-}$or $\mathrm{O}^{2-}$ and anionic vacancies. 

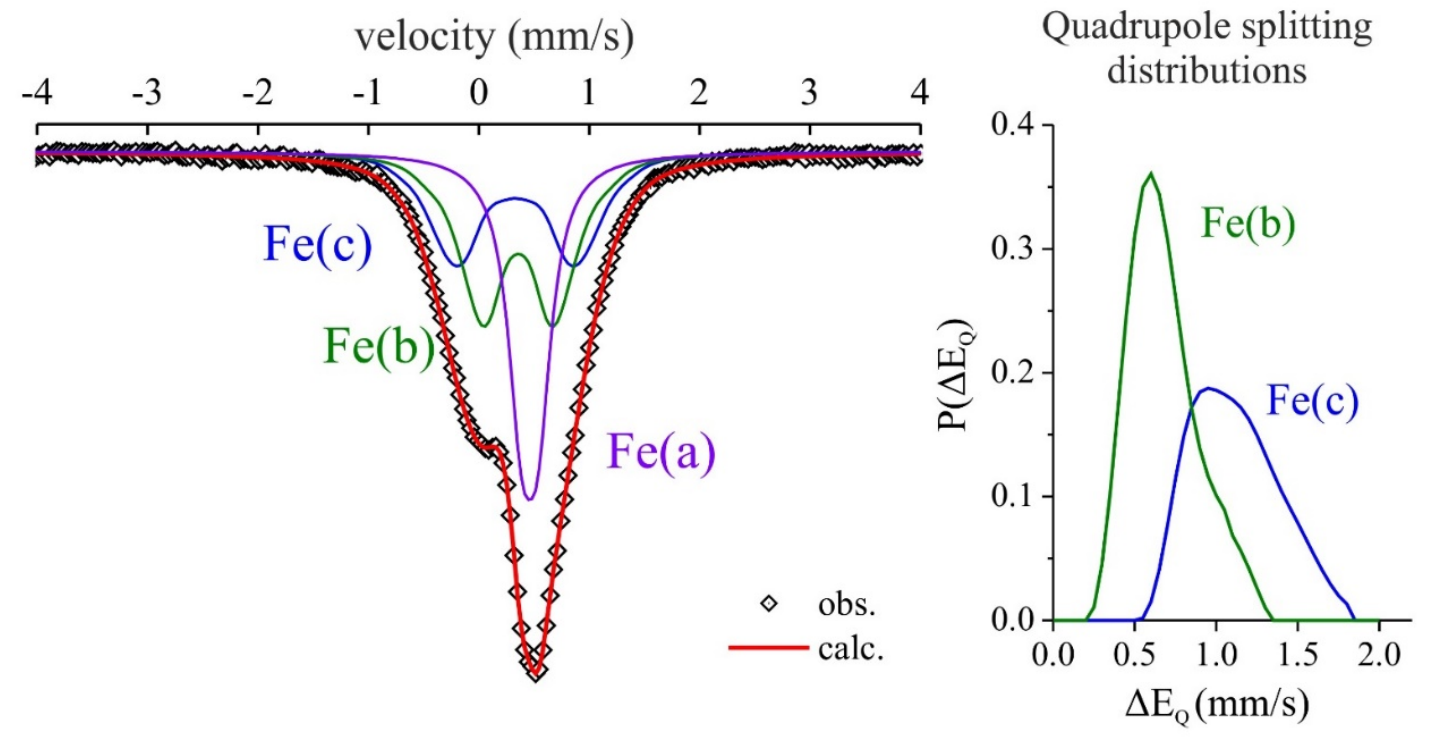

Figure S2. ${ }^{57} \mathrm{Fe}$ Mössbauer spectra of $\mathrm{HTB}-\mathrm{FeF}_{3-x} \mathrm{O}_{x / 2} \square_{x / 2}$ obtained after a post-thermal treatment. Right panel: Quadrupole splitting distributions.

Table S1. ${ }^{57}$ Fe Mossbauer parameters obtained from the reconstruction of spectra shown in Figure S2. *Average value.

\begin{tabular}{|lllllll|}
\hline & $\boldsymbol{\delta}(\mathrm{mm} / \mathrm{s})$ & $\boldsymbol{\Delta} \mathbf{E}_{\mathbf{Q}}(\mathrm{mm} / \mathrm{s})$ & $\boldsymbol{\Gamma}(\mathrm{mm} / \mathrm{s})$ & Area (\%) & Assignments & Environments \\
\hline $\mathrm{Fe}(\mathrm{a})$ & $0.46(1)$ & $0.15(1)$ & $0.30(1)$ & 34 & Six-fold coord. $\mathrm{Fe}^{3+}$ & $\mathrm{FeF}_{6}$ \\
$\mathrm{Fe}(\mathrm{b})$ & $0.38(1)$ & $0.68^{*}$ & $0.30(-)$ & 38 & Six-fold coord. $\mathrm{Fe}^{3+}$ & $\mathrm{FeF}_{6-\mathrm{x}}(\mathrm{OH})_{\mathrm{x}}$ \\
$\mathrm{Fe}(\mathrm{c})$ & $0.34(1)$ & $1.11^{*}$ & $0.30(-)$ & 28 & Five-fold coord. $\mathrm{Fe}^{3+}$ & $\mathrm{FeF}_{4} \mathrm{O}$ \\
\hline
\end{tabular}

\section{$\underline{\text { Electrochemical properties }}$}

To probe the impact of the presence of anionic vacancies on the electrochemical properties, electrodes using $\mathrm{FeF}_{3-\mathrm{x}}(\mathrm{OH})_{\mathrm{x}} \cdot n \mathrm{H}_{2} \mathrm{O}$ and $\mathrm{FeF}_{3-x} \mathrm{O}_{x / 2} \square_{x / 2}$ as active materials were tested in lithium cells. Equal electrode processing (hand milling) and operating conditions (50 mA.g ${ }^{-1}, 2.0 \mathrm{~V}-4.2 \mathrm{~V}$ voltage window) were used. The galvanostatic discharge and charge curves for the first cycle are gathered in Figure S3. In agreement with our previous study, the $\mathrm{FeF}_{3-x} \mathrm{O}_{x / 2} \square_{x / 2}$ electrode shows a significant improvement in terms of lithium insertion compared to the vacancy-free compound. ${ }^{1,2}$ The $\mathrm{FeF}_{3-x} \mathrm{O}_{x / 2} \square_{x / 2}$ electrode showed high reversibility, with the insertion of up to $0.7 \mathrm{Li}^{+}$per $\mathrm{Fe}(166 \mathrm{mAh} / \mathrm{g})$ during the first discharge and $0.6 \mathrm{Li}^{+}$ (140 mAh/g) upon charging. 


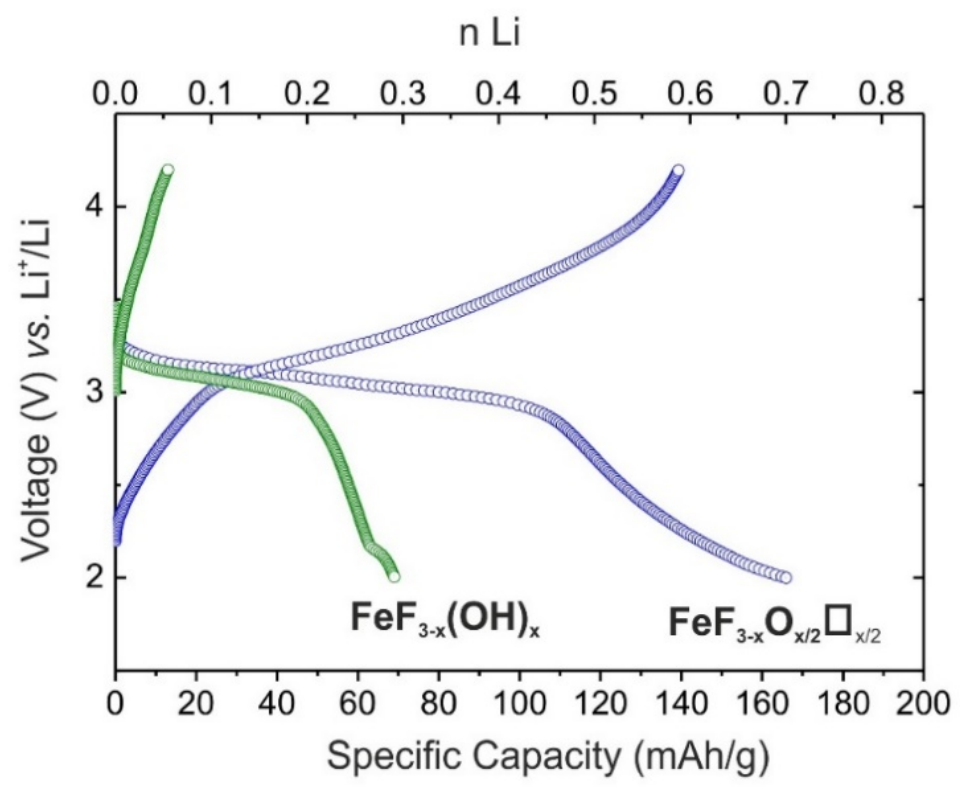

Figure S3. First discharge and charge curves for $\mathrm{Li} / \mathrm{FeF}_{3-\mathrm{x}} \mathrm{O}_{\mathrm{x} / 2} \square_{\mathrm{x} / 2}$ (blue) and $\mathrm{Li} / \mathrm{FeF}_{3-\mathrm{x}} \mathrm{OH}_{\mathrm{x}}$ (green) cells cycled under $50 \mathrm{~mA} \cdot \mathrm{g}^{-1}$.

\section{$\underline{\text { DFT calculations }}$}

\section{Single-vacancy dehydroxylated $\mathrm{FeF}_{3}$}

To model the formation of a single anion vacancy in a hydroxyfluorinated cell, we performed a sequence of DFT calculations, starting with a configuration containing two $\mathrm{OH}^{-}$substitutions: $\mathrm{Fe}_{12} \mathrm{~F}_{46}(\mathrm{OH})_{2}$ (Figure S4, left panel). We then removed $\mathrm{H}+\mathrm{OH}$ to form a dehydroxylated cell with stoichiometry $\mathrm{Fe}_{12} \mathrm{~F}_{46} \mathrm{O}_{1} \square_{1}$, containing one $\mathrm{Fe}-\mathrm{O}-\mathrm{Fe}$ oxo-bridge and one anionic vacancy, $\mathrm{Fe}-\square-\mathrm{Fe}$ (Figure S4, middle panel). Performing a geometry optimization on this dehydroxylated structure, we identified a relaxation of the $\mathrm{F}$ anions close to the vacancy, corresponding to $\mathrm{FeF}_{5}+\mathrm{FeF}_{5} \mathrm{O} \rightarrow \mathrm{FeF}_{6}+\mathrm{FeF}_{4} \mathrm{O}$ change in the $\mathrm{Fe}$ coordination environments, and forming a $\mathrm{FeF}_{4}-\mathrm{O}-\mathrm{FeF}_{4}$ bipyramidal unit (Figure S4, right panel). The five-fold coordinated $\mathrm{Fe}^{3+}$ have square-pyramidal coordination geometries. To estimate the relaxation energy associated with this reorganization we performed a second geometry optimization starting from the original dehydroxylated structure, ensuring that the original coordination environment was preserved. The resulting structure, with the oxygen vacancy in the original as-formed position, was $0.40 \mathrm{eV}$ higher in energy than the fully relaxed structure. 


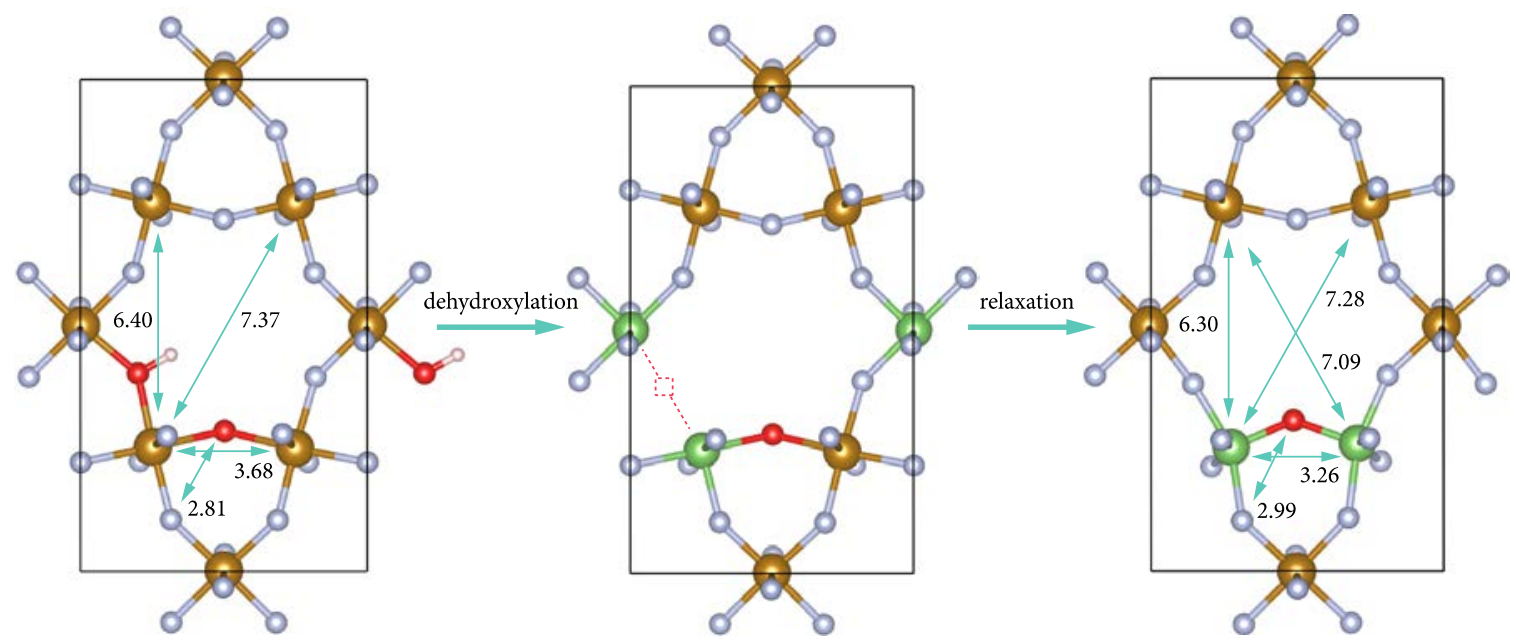

Figure S4. Left panel: optimized structure of the $\mathrm{Fe}_{12} \mathrm{~F}_{34}(\mathrm{OH})_{2}$ cell. Middle to right panels: evolution of the structure of the $\mathrm{Fe}_{12} \mathrm{~F}_{34} \mathrm{O} \square$ cell before and after relaxation. Views are along the $c$-axis. Distances are given in Angstroms. The structure files used to generate this figure are available under CC-BY-4.0 [3].

\section{Fe coordination environment DOS analysis}

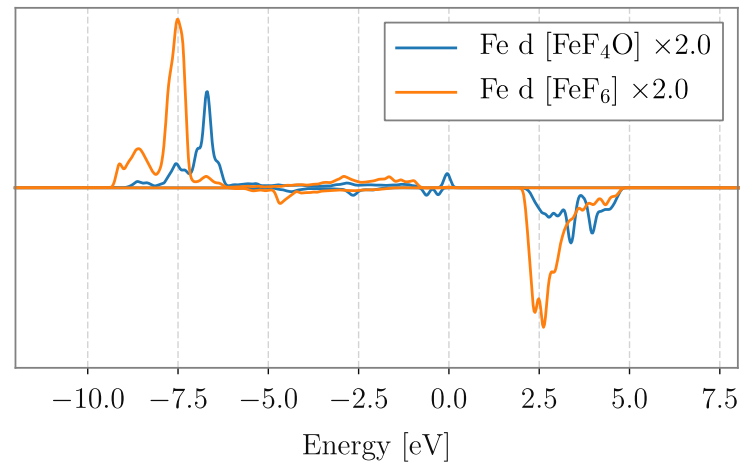

Figure S5. PBEsol projected densities of states for the Fe d states, differentiating between Fe centres with $\mathrm{FeF}_{4} \mathrm{O}$ coordination (blue) and $\mathrm{FeF}_{6}$ coordination (orange). Source: source data, figure files, and plotting scripts are available under CC-BY-4.0 [3].

\section{References}

(1) Duttine, M.; Dambournet, D.; Penin, N.; Carlier, D.; Bourgeois, L.; Wattiaux, A.; Chapman, K. W.; Chupas, P. J.; Groult, H.; Durand, E.; et al. Tailoring the Composition of a Mixed Anion Iron-Based Fluoride Compound: Evidence for Anionic Vacancy and Electrochemical Performance in Lithium Cells. Chemistry of Materials 2014, 26 (14), 4190-4199.

(2) Dambournet, D.; Chapman, K. W.; Duttine, M.; Borkiewicz, O.; Chupas, P. J.; Groult, H. Lithium Insertion Mechanism in Iron-Based Oxyfluorides with Anionic Vacancies Probed by PDF Analysis. ChemistryOpen 2015, 4 (4), 443-447.

(3) Morgan, B., 2018. DFT dataset: Impact of Anionic Vacancies on the Local and Electronic Structures of Ironbased Oxyfluoride Electrodes. University of Bath Research Data Archive. https://doi.org/10.15125/BATH00576. 